\title{
Research on the Development of College Sports Digital Model in Shandong Province in the Construction of Smart Campus
}

\author{
Ren Huiyi, Song Liwei, Chang Baofang \\ Department of Physical Education, Jining University, Qufu, China \\ Email address: \\ renhuiyi@sina.com (Ren Huiyi), songlw2004@163.com (Song Liwei), cbf1980@163.com (Chang Baofang) \\ To cite this article: \\ Ren Huiyi, Song Liwei, Chang Baofang. Research on the Development of College Sports Digital Model in Shandong Province in the \\ Construction of Smart Campus. Science Innovation. Vol. 9, No. 5, 2021, pp. 204-209. doi: 10.11648/j.si.20210905.15
}

Received: September 9, 2021; Accepted: September 29, 2021; Published: October 19, 2021

\begin{abstract}
This paper investigates the sports construction of some colleges and universities in Shandong Province, discusses the problems and trends of college sports development mode in the current construction of smart campus in Colleges and universities, and finds that at present, the sports teaching of some colleges and universities in Shandong Province is still in the management mode with teachers as the main body, the construction of relatively single management platform, and the construction of various links of sports has not formed interconnection. Through the research methods of literature, investigation and comparison, this paper puts forward that on the basis of the existing physical education teaching environment and resources, College Physical Education in Shandong Province should use digital information technology to aggregate and empower, and coordinate the comprehensive cooperation of physical education teaching resources, methods, management, evaluation and services. Through the digital transformation of physical education, we should seek to establish a comprehensive, interconnected, safe Efficient college sports model. This paper also makes a certain theoretical demonstration on the guiding ideology, significance, basic ideas, preconditions, specific measures and expectations of the construction of college sports digitization mode, and expects this paper to provide some help to the construction of college sports digitization and smart campus.
\end{abstract}

Keywords: Smart Campus, College Sports, Digital, Model, Shandong

\section{智慧校园建设中山东省高校体育数字化模式发展研究}

任慧一，宋丽维，常宝芳

济宁学院体育学院, 曲阜, 中国

\section{邮箱}

renhuiyi@sina.com (任慧一)，songlw2004@163.com（宋丽维）, cbf1980@163.com（常宝芳）

摘要：本文对部分山东省高校的体育建设进行了调研，探讨在当前高校智慧校园建设中高校体育发展模式的问题与趋 势, 发现目前山东省部分高校的体育教学依然处于以教师为主体的管理方式, 较为单一的管理平台建设, 体育各环节 建设未形成互联等现象。通过文献资料法、调查法和比较法等研究方法, 提出: 山东省高校体育在现有体育教学环境 与资源的基础上，利用数字信息技术聚合与赋能，统筹体育教学资源、方式、管理、评价与服务等全面的协作，通过 体育数字化转型，应当寻求建立一种全面、互联、安全、高效的高校体育模式。本文还对构建高校体育数字化模式的 指导思想、意义、基本思路、前提条件、具体措施及预期等进行了一定的理论论证，期望本文对高校体育数字化和智 慧校园建设提供一定的帮助。 
关键词: 智慧校园, 高校体育, 数字化, 模式, 山东省

\section{1. 引言}

学校体育是教育的重要组成部分, 学校体育不仅增进 青少年体质, 提升他们的身体机能, 还具有德育培养的属 性, 是智育学习的保障, 更是学生、家庭和社会联系的紧 密纽带, 建设和谐社会的重要基础。2012年, 教育部颁布 《教育信息化十年发展规划（2011-2020年）》中就指出: “以教育信息化带动教育现代化, 促进教育的创新与变 革”[1]。近年来,数字信息技术在我国教育革新领域得到了 广泛地应用。扩大互联网和数字信息技术在高校体育中应 用的广度和深度, 是推动和发展高校体育的重要途径。 2018年6月, 国家市场监督管理总局、中国国家标准化管 理委员会公布了《智慧校园总体框架(GBT36342-2018)》 [2], 智慧校园陆续在高校建设中如火如茶的开展起来。在 对山东省部分高校体育工作进行了较为广泛地调研后发 现, 当前高校体育工作面临着诸多问题, 主要体现在“教 与学”的主体问题, 教学效率和效果的问题, 体育管理的 问题, 体育安全的问题等。虽然, 大部分高校体育工作中 已经引入了一定的现代数字信息技术, 例如网络教学、视 频采集、计算机辅助等, 但这些单纯地以高校体育实现教 学信息化、数据可视化等为目标的初步智能化措施, 对提 升高校体育教学效率和效果, 体育管理和安全等成效有 限, 更难以满足高校体育应对智慧校园建设的需求。笔者 认为, 在国家现行教育方针和政策的指导下, 高校体育在 资源管理、教学方式、人才培养、信息采集及评价等方面 不能仅仅停留于信息化手段的改变, 建议在现有体育教学 环境与资源的基础上利用数字信息技术聚合与赋能, 统筹 体育教学资源、方式、管理、评价与服务等全面的协作, 通过体育数字化转型, 寻求建立一种全面、互联、安全、 高效的高校体育模式。本文研究探讨构建高校体育工作数 字化平台, 利用数字信息技术促进高校体育工作的各个环 节相互协作, 建立与外部世界互联互通, 资源共享, 从而 进一步提升师生的教与学水平, 建立科学、安全、有效的 管理方式, 并在体育理论的基础上, 在智慧校园建设的春 风下, 助力高校体育工作数字化建设的实践与推广。

\section{2. 高校体育发展模式的问题}

\section{1. 以教师为中心的管理方式}

高校教育管理对象具有差异性，所以因材施教、个性 化管理和多样化人才培养一直是教育的理想。[3]随着我国 教育体制改革的不断深入以及信息化技术的广泛应用, 学 校体育也逐步进行了发展模式的创新, 例如“三自主”的教 学模式, 即由学生“自主选择课程内容、自主选择任课教 师、自主选择上课时间”。“三自主”体育教学模式的实施, 目的是结合学生自身体育兴趣的同时, 有效地调动起学生 的锻炼积极性, 提高体育课程实施的效率和效果, 从而引 导学生形成终身体育的意识。“三自主”体育教学模式与早
前的传统体育教学模式相比, 学生有了一定的自主选择 权, 课堂内容和上课形式上出现了一定的革新。但在实际 教学应用过程中则发现, 山东省部分高校体育建设中仍存 在着一些尚未解决的现实问题: 例如理论学习与实践活动 脱节, 课上教得多, 练得少; 学生个人运动能力与课程设 置、师资能力不相称; 师资力量与专业和学生的需求不匹 配; 体育教材和资源的利用率差; 体育测量与评价的主观 臆断和盲从等。这些问题依然没有从根本上改变以“教师 为中心”的管理方式, 最终还是导致了学生们运动时间被 大大压缩, 运动兴趣较低, 越来越多的学生虽然选择了自 己喜爱的体育课程, 但依然“宅”在室内或者排斥体育锻 炼, 甚至热爱运动的学生因教学无法满足自己的期望而漠 视体育教学, 学生对体育评价的手段和结果存在质疑等。 这种管理方式并没有真正实现以“学生为主体”的教学原 则, 缺乏对开放、包容的教学方式的支持, 缺乏支持平台 化对接的适应能力。体育教学方式变革的核心在于教学理 念的改变, 运用发展的理念助推教学方式的变革, 放眼于 学助力于教。[4]

\section{2. 较为单一的管理平台建设}

据调查, 当前山东省诸多高校实现了体育教学管理平 台建设, 在一定程度上提升了体育教学效率和人才培养能 力, 形成了一定的内部教学协调的闭环管理。但是, 这种 平台模式往往是以传统的计算机单一网络平台建设为主, 数据采集、交换和分析较为封闭。缺乏对学生学习行为数 据合理的整合管理模式, 易造成信息孤岛, 无法准确分析 学生学习行为数据, [5]只是简单实现了体育老师的排课和 授课学生的选课等系统衔接, 尚未具有数据分析、智能规 划的功能, 且接口部分与学校整体的教学平台难以对接 等, 在智慧校园建设中不少高校存在的问题已经凸显。笔 者认为: 高校体育不同于其他基础学科的智慧化环境建 设, 基于其属性与功能, 它还肩负着师生核心素养、思政 教育、体医融合、终身体育等全方位体系建设, 培养全面 发展的接班人和建设者的重任。同时, 智慧校园建设的核 心是为广大师生实现全面的智能感知环境和综合信息服 务平台以及广泛地应用与服务领域, 并为学校与外部世界 提供互联和协作, 学校体育以单一的管理平台建设已然无 法适应智慧校园建设的大环境。

\section{3. 高校体育各环节建设未形成互联}

在山东省部分高校的体育教学中, 由于体育资源利 用, 师资力量调配, 师生交互式学习的主体错位等问题, 造成了学校体育教学与管理之间的分割, 依然存在体育资 源无法合理利用, 师资力量较难满足逐年扩充的授课学 生, 并没有从根本上改变以“学生为主体”的交互式学习方 式等问题, 从而造成师生的教学反馈与评价不对称。同时, 
学校管理的各个环节之间分属于不同的信息管理系统, 例 如排课系统、教学管理系统、师生互评系统等等, 各个系 统之间不能实现有效互联, 不能实现有效的实时链接, 这 也也给学校带来诸多的效率问题和资源浪费。特别是 2020 年初开始的新冠肺炎疫情, 高校体育教学在统一平台下开 展师生校外线上教学、学生居家课程实践和在线体育教学 评价等方面急需进行突破, 这些新的变化不仅对高校体育 的智慧化建设提出了更高的要求, 也是高校体育数字化发 展建设必须面对和迫切解决的问题。

\section{3. 高校体育数字化模式的构建}

\section{1. 高校体育数字化模式的指导思想}

2020年8月31日，体育总局、教育部印发《关于深化 体教融合促进青少年健康发展的意见》中指出: “深化体 教融合促进青少年健康发展, 要树立健康第一的教育理 念, 推动青少年文化学习和体育锻炼协调发展, 加强学校 体育工作, 完善青少年体育赛事体系, 帮助学生在体育锻 炼中享受乐趣、增强体质、健全人格、锻炼意志, 培养德 智体美劳全面发展的社会主义建设者和接班人”[6]。早在 《智慧校园总体框架》颁布之前, 国家就对信息数字教育 发展做出了规划与部署, 2017年, 国务院印发的《新一代 人工智能发展规划》中提出“利用智能技术加快推动人才 培养模式、教学方法改革, 构建包含智能学习、交互式学 习的新型教育体系”[7]。在这样的时代背景下, 高校体育 应紧随数字信息科技的发展, 构建个性化学习与终身化发 展的体育教育体系, 推动高校体育由低层次、粗放型向高 层次、精准型的转变。

\section{2. 构建高校体育数字化模式的意义}

作为国家优秀人才培育基地的高校, 责无旁贷地应将 这些目标的达成落实在自身的发展中, 明晰新时代高校人 才培养的新使命、新责任。[8]以往在高校体育建设中探讨 较为广泛地是教学方式的改革, 例如较早的“三自主”体育 教学模式, 人才培养模式以及近期较为关注的线上体育教 学等, 这些符合以往我国教育改革的思路与需求。但《教 育信息化十年发展规划（2011-2020年）》中强调，应以“优 质教育资源和信息化学习环境建设为基础, 以学习方式和 教育模式创新为核心”[1]。智慧校园是以促进信息技术与 教育教学融合、提高学与教的效果为目的, 以物联网、云 计算、大数据分析等新技术为核心技术, 提供一种环境全 面感知、智慧型、数据化、网络化、协作型一体化的教学、 科研、管理和生活服务, 并能对教育教学、教育管理进行 洞察和预测的智慧学习环境。[9]笔者认为: 在当前的智慧 校园建设中, 单一体育教学模式已然略显滞后, 无法有效 提升高校体育的功能, 也无法契合当前的智慧校园建设的 趋势。高校体育应尝试借助数字信息技术建立开放、包容 的教学方式, 推动体育交互式学习和个性化学习, 从而真 正实现以“学生为主体”的体育教学方式; 以大数据和人工 智能为基石, 为师生教学、健身提供科学的数字化管理、 服务和安全保障等; 学校体育数字化模式还能够应使用智
慧校园的管理随需而变、协作统一、赋能创新, 助力推动 智慧校园的整体建设。

\section{3. 高校体育数字化模式构建的前提}

高校体育数字化模式构建的前提是高校体育数字化 转型。高校体育的发展强调教学效率、效果、管理和评价, 体育数字化转型的目的是提升体育教学的效率与效果, 加 强体育管理, 满足体育服务需求, 完善科学、精准、有效 地评价体系等。因此, 高校体育数字化转型是建立在数字 化转换、数字化升级的基础上, 进一步提升高校体育的核 心功能, 形成B端（校际之间）和C端（学校师生）的数 字化体系, 这是构建体育数字化模式的重要基础。高校体 育数字化转型有两个维度的变化, 一是纵向的维度: 进一 步根据不同的体育场景需求应用不同的数字化技术手段, 例如人工智能技术的体育选课系统、云处理的视频互动教 学、大数据分析的身体机能适应强度和目标等等; 二是横 向的维度: 利用物联网、云计算、人工智能、大数据等技 术进行横向的聚合与赋能, 实现体育教学资源、师生教学、 体育管理、体育评价、体育服务、体育安全等方面的链接, 实现全要素之间的一种数字化关系, 并且通过利用学校内 部服务（B2C）及学校外部交流（B2B）的运行产生的各 种大数据, 寻求建立一种开放、共享的体育数字化管理与 服务新模式。简言之, 高校体育实现数字化转型的目的就 是改变高校体育以往数字化不完整, 数字化之间没有关联 性的分割局面, 发挥高校体育各要素之间相互支持的价值 作用。

\section{4. 学校体育数字化转型与构建的基本思路}

促进高校体育的科学发展是本文研究的目的和目标, 数字信息技术的应用是解决当前高校体育问题的一种可 以尝试的手段与方法。当下高校体育亟待解决的是规划、 应用、评测和拓展的互联和效能问题, 数字化模式可以在 科学规划、高效利用、智能教育和空间拓展等方面为高校 体育的发展提供有力的支持和帮助。体育数字化模式的基 础是基于物联网、人工智能、大数据等技术手段支持下的 综合管理与服务平台，把体育资源、体育教学、体育管理 和服务、课外（校外）体育等环节基于一体，通过资源、 信息、数据的分配与共享, 有效利用和拓展体育资源, 提 高师生教学效率和效果, 对教学成果进行客观、科学的评 价等。

\section{4. 学校体育数字化模式的具体措施}

\section{1. 体育资源的数字化转型}

传统的体育资源往往是指学校的体育器材、体育场 地、投入资金、体育师资等。体育资源的数字化转型首先 是把学校的固有体育器材、设施、场地登记造册, 通过物 联网来管理现有固定资源的利用和分配, 减少人工成本, 提高工作效率。通过大数据分析, 为学校提供现有固定资 源与现有师生的配比, 及时为学校体育资金的投入提供合 理的规划, 减少盲目投资。进一步扩大资源范畴, 把体育 教材、人才培养方向等进行数字化信息处理, 形成学校体 
育理论数据库, 甚至可以通过校际之间的对接, 形成更加 广阔的资源信息库, 为广大师生提供更加全面、科学和前 沿的理论指导; 并通过大数据分析, 形成更加适应本学校 特点的人才培养规划。众所周知, 现今高校体育师资紧张, 通过人工智能技术可以辅助学情分析, 合理分配现有的师 资资源, 甚至可以通过相近校际之间的互联, 构建师资数 据库, 形成师资的共享, 在一定程度上也能够弥补师资短 缺的问题等。

\section{2. 体育教学的数字化转型}

体育教学的数字化转型是利用数字化技术, 体育教师 把教学内容批量视频化并传入云端, 学生通过 $\mathrm{C}$ 端系统登 陆自己选择的体育项目进行线上视频学习并计入学时, 这 在一定程度上大大提升了学习时间的机动性和便利性, 同 时可以减少教师在线下体育课程中较多重复的授课内容。 线下课堂的更多时间是与学生进行答疑和纠错的交互, 具 有较强的针对性和具体性, 大大提高了线下课程的效果。 教师在新的时代背景下需要适应这个时代的教学观, 将以 往灌输式的教学方法转变为注重学生深度学习和个性化 学习的新方法。[10]学生还可以根据自己的基础水平选择 线上不同的体育教学内容, 例如篮球教学, 有一定基础的 学生可能就不再选择学习初级的运球或者传球了, 而是直 接去选择自己更感兴趣的战术学习等, 这样大大提高了学 习的效率且节省了学习资源。这样一种转型是对体育课的 一种新的探讨, 体育课中教师逐渐转变为是一种辅助角色 而不再是以往课上的“指挥家”, 学生成为主体, 通过教师 解决对教学内容不同的认识和理解问题。《学校体育学》 中也指出: “体育教学应遵循以学生发展为中心, 重视学 生的主体地位。核心是满足学生的需要和重视学生的体 验”[11]。线下课程中教师通过学生对线上学习的消化和吸 收对学生进行教学评价, 争取更多的时间积极组织学生参 与心肺功能身体训练, 贯彻《高等学校体育工作基本标准》 中“每节体育课须保证一定的运动强度, 其中提高学生心 肺功能的锻炼内容不得少于 $30 \%$ ”[12]的规定。学生也可以 通过线上教师的视频教学和线下的答疑、纠错及训练手段 对教师进行教学评价。视频教学内容的上传是检验教师教 学能力的重要窗口, 同时在校际互联的数字化模式下, 学 生甚至可以选择外校更高水平教师的课程, 这在一定程度 上扩展了学生自主学习的广度和深度, 也提升了教师对自 身业务能力的要求。高校教育改革使得学生主体地位得以 凸显, 并且借助“互联网+”这一模式, 也能够有效规避以 往传统的填鸭式教学, 逐渐突破课堂教学的束缚, 师生在 教学中的角色出现变化, 这对于整个高校教育而言是一种 挑战，同时也是一种机遇。[13]由于线上教学的介入，大 大提升了体育教学效率, 因此, 笔者认为可以尝试调整线 下课程的次数和时长。目前, 山东大部分高校的体育课多 为一周一次, 一次两学时连堂 (约100分钟), 课上依然 延续着传统的体育课堂常规。由于课堂时间太长, 体育教 学往往比较拖沓, 特别在天气炎热或者寒冷的时节, 体育 教学和心肺功能训练的效果基本无法保证; 同时, 一周一 次体育课, 过长的间隔时间也不利于体育教学的延续性。 体育教学数字化转型后, 线上学习计入学时, 线下教学可
以尝试一周两次, 一次一学时 (约50分钟)。一方面提高 了学生每学期的体育教学学时, 进一步保证了学习的效 果; 另一方面使线下体育课的排课更加机动和灵活。在对 部分山东高校体育课程排课的调研中发现, 很多高校都有 自己的体育排课系统, 但每到排课时依然困难重重, 捉襟 见肘。究其原因是, 现如今高校各学科的专业课程十分密 集且课程种类较多, 学校教务往往是先排各自的专业课程 再排体育课程; 同时, 为了提升体育教学效果, 现各高校 的体育课程大多是体育选项课的形式, 即学生根据自身的 兴趣和时间来选择体育教师和体育项目。这两方面的原因 造成了很多高校的学生其实并不能在自己有限的空余时 间选择符合自己兴趣的体育课, 体育选项课名不副实, 学 生的学习动力大打折扣, 教学效果也可想而知。如果采取 了线上、线下教学的方式后, 线下教学的属性发生了一定 的改变, 线下教学主要是解决学生困惑和进行心肺功能训 练, 因此课程安排更加具体化、专业化和个性化。再者, 改为一周两次体育课, 一方面增强了学生学习的延续性, 另一方面可以增加体育排课系统的灵活性, 优化师资的分 配, 缓解师资紧张的局面, 让排课不再成为一项难题。

\section{3. 体育管理的数字化转型}

学生方面。在对山东部分高校体育管理的调查中发 现, 不少高校的体育管理尚处于初级阶段, 只是对学生的 兴趣选项、考勤、考试等进行了统计与管理。这种管理的 作用也只能作为考核的一种备份和查询而已。体育管理的 数字化转型是在遵守法律和尊重隐私的前提下进行学生 的大数据管理, 不仅现有的体育数据信息还需要包括基础 生理数据（在自愿的情况下可以扩展到疾病数据）、身体 素质数据、体质测试数据, 甚至兴趣爱好、学科专业等数 据, 建立学生身体素质数据库, 以便于学校和教师通过大 数据分析为体育教学做出规划, 通过人工智能技术为广大 学生推送运动强度建议和运动训练方案, 甚至可以根据学 生个体的生化数据来设置运动预警, 为广大学生提供运动 安全防护等。同时, 体育管理的数字化转型可以推动智慧 校园建立学校健康数据库, 为B端用户 (校方) 的医疗、 卫生和防疫提供支持和保障。

教师方面。在对山东部分高校体育管理的调查中也发 现, 体育教师相似高校体育管理中的参与度较少。体育数 字化模式的主体架构是一个开放式平台, 教师和学生一样 都是 C端用户。前文已提, 体育教学数字化需要教师上传 教学视频, 这样就会逐渐形成一个庞大的体育教学数据 库, 也可以通过B端端口形成校际之间的互联。教师可以 进行较为广泛地业务学习和交流, 不断优化和提高自身的 业务水平。同时, 大数据和人工智能技术可以提供不同场 景需求的较为真实、可靠的大数据分析, 为广大教师进行 科研工作提供便利和支持。

\section{4. 体育评价的数字化转型}

改变当前高校体育评价体系主要是以教学评价、考核 评价为主, 教学评价是基于教师对学生评价、学生对教师 评价、学校对教师评价等, 考核评价主要是通过考核对学 生的学习过程进行评价。《高等学校体育工作基本标准》 
中强调“将学生体质健康状况作为衡量学校办学水平的重 要指标。将体质健康状况、体育课成绩、参与体育活动等 情况作为学生综合素质评价的重要内容”[12]。所谓“学生 综合素质评价”是一项多要素构成的评价体系, 需要大量 的现实数据给予支撑, 才能较为全面、真实地反映学生的 情况, 这需要大量的数据采集与分析; 同时, 通过人工智 能技术对学生基础数据的深度学习, 客观真实地记载每个 学生成长发展的轨迹。这将彻底改变人们对学校体育教育 的认识和态度, 从而实现学校体育教育教学被动笊尤局面 的根本性。[14]从而, 为教师和学校提供较为客观地教学 规划、参考和预测, 减少教师对学生身体机能的人为误判。 体育评价的数字化转型还可以进一步规避学生评教、校方 评教中较多人为因素影响, 为教师提供业务学习和实践平 台的同时, 充实体育教师职称评定、学术评价、岗位聘任 和学习进修等管理制度中的可靠依据。因此, 现行的体育 评价方式也需要进行一定的提升和转变。

\section{5. 高校体育数字化模式的预期}

\section{1. 学校内、外部体育资源的互联互通}

在互联网环境下, 未来高校所有的教学活动都可以依 托于数字化的平台模式, 也就是高校的许多业务活动都是 平台对平台的关系。学校仅需要借助自己的数字化平台, 与内、外部体育资源平台的对接, 实现资源共享。数字信 息技术的快速发展, 已经在为高校重构体育数字化模式创 造了条件。

\section{2. 提高学校运行效率, 节省资源}

在智慧校园建设中, 在内、外体育资源的互联互通基 础上, 高校可以借助统一的数字化平台, 打通学校各个教 学环节和要素之间的链接。通过这种打通与连接提升高校 的运行效率以及有效节省资源, 包括教育资源、师资资源、 财政资源等。高校体育数字化的基本环节是改变中间的管 理职能, 在互联的环境下, 可实现高校与 $\mathrm{B}$ 端 (校际) 和 的 $\mathrm{C}$ 端 (师生) 直接衔接, 借助数字化信息技术体系, 以 数字化为核心构建完整的体育管理体系, 实现减少层级、 提升效率、节省资源的学校管理目标, 这种衔接可以想象 会对高校体育发展的提升与改变带来质的飞跃。

\section{3. 体育管理与服务职能并存}

体育数字化模式下管理职能是在广泛数据的支撑下 体现出来的, 数字化信息技术使传统的管理走向了智慧 化, 改变以往体育管理人为因素的干扰和数据的简单列式 化的现状, 并通过管理大量的数据源, 形成聚合而不再只 是课程考核的依据。聚合的目的是赋能。体育数字化模式 与传统模式相比, 在大量的数据支撑与分析系统支持下, 体育服务职能得到充分的体现。例如: (1) 体育规划服 务。学生可以根据自身身体素质和生化数据分析系统的结 果, 参考性的选择适宜的运动项目、运动强度等, 基本实 现“个性化”的学习, 提升学习效率和效果。（2）体育知 识服务。通过B2B的校际链接, 学生或者教师可以获得海 量的体育知识推送, 这对于体育人才培养, 甚至核心素养
的提升有着显著的提高; 同时, 教师也可以获得更多地专 业技术支援, 不断提高自身的教学和科研能力。（3）体 育安全保障服务。众所周知, 当今大学生身体素质参差不 齐, 多有身体肥胖, 近视和营养失衡的现象, 甚至也有三 高疾病的频发等, 这些受到了家庭和社会的广泛关注, 这 对高校体育的大学生身体健康保护提出了更高地要求。

《高等学校体育工作基本标准》中强调“健全学校体育保 障机制, 加强学校体育活动的安全教育、伤害预防和风险 管理”[13]。通过大学生身体生化、体质等综合数据的数字 化转型, 大数据分析和人工智能技术可以辅助学校和教师 及时预判学生的运动风险和身体隐患, 提前做出有效地运 动规避和调整，防范于未然。

\section{6. 结论}

本文通过对山东省部分高校体育工作的调研, 结合国 家教育政策和体育理论知识, 探讨了当前高校体育工作中 依然存在的问题, 并提出应利用数字信息技术尝试构建全 面的高校体育数字化模式。通过论证与分析得出：高校体 育亟待解决的是提升“教与学”的效率和效果, 科学、安全 的管理方式、准确、有效的评价体系等, 这些方面的改进 需要全面的高校体育数字化转型。体育数字化模式是在数 字化转型的基础上, 利用数字技术, 对学校体育的资源利 用、教学方式、管理与服务进行系统化、整体性的转型与 变革, 进而打造以个体与团队, 学生与学校, 学校与社会 为一体的多维度体育管理与服务模式。《国家中长期教育 改革和发展规划纲要（2010-2020年）》中明确提出：“信 息技术对教育发展具有革命性影响”[15]。当今是数据的时 代, 高校体育建设理应在智慧校园建设中, 主动尝试与数 字信息技术的碰撞, 主动尝试数字化升级与转型。目前, 高校体育数字化模式尚处于理论探讨和摸索阶段, 亟待进 行广泛地实践工作加以佐证, 这样才能更好地贯彻“创新 教育教学方式, 指导学生科学锻炼, 增强体育教学的吸引 力、特色性和实效性。建立体育教研、科研制度, 形成高 水平研究团队, 多渠道开展以提高学生体质健康、教学质 量、课余训练、体育文化水平等为目标的战略性、前瞻性、 应用性项目研究, 带动学校体育工作整体水平提高”[12] 的国家学校体育工作规划与发展方针。

\section{致谢}

感谢山东省社会科学界联合会、济宁市科技局、济宁 学院对青少年体育教育的高度关注, 以及对智慧高校体育 数字化研究的大力支持。上述单位分别于 2020 年批准 “智 慧校园建设背景下山东省学校体育数字化模式发展研究” (20CSDJ07) 为山东省社会科学规划项目立项, 2019年 批准 “基于人工智能的青少年体育教育健身服务云平 台”(2019ZDGH032) 为济宁市重点研发计划项目立项, 2019年批准“山东省体育教育专业实习支教学生基层意识 培养机制研究” (JX201905) 为济宁学院教学改革项目立 项, 并取得了一定的研究成果。期望课题研究为高校体育 数字化建设, 青少年体育健身和大学生培养提供一定的帮 助和支持。 


\section{参考文献}

[1] 教育信息化十年发展规划（2011-2020 年） [EB/OL].[2012-03-13].http://old.moe.gov.cn//publicfiles/busi ness/htmlfiles/moe/s5892/201203/xxgk_133322.html.

[2] 国家市场监督管理总局,中国国家标准化管理委员会.智慧 校园总体框架(GBT36342-2018)[S]. 北京: 中国标准出版社, 2018。

[3] 杨阳,苏力,石城.大数据对现代高校教育管理的影响及改进 策略[J].江苏高教,2019,(3):58-61。

[4] 王广否,李晓静,宋旭,滚军军.信息化背景下大学体育教学方 式变革研究[J].山东体育学院学报,2018,(1):134-13。

[5] 沈贵庆.大数据分析在高校智慧教育中的应用研究 [J].现代 电子技术,2019,42(4):97-100。

[6] 体育总局, 教育部.关于印发《深化体教融合促进青少年健 康发展意见》的通知 [EB/OL].[2020-08-31].http://www.moe.gov.cn/jyb_xxgk/moe _1777/moe_1779/202009/t20200922_489794.html.

[7] 新一代人工智能发展规划 [EB/OL].[2017-8-15].http://www.gov.cn/zhengce/content/201 7-07/20/content_5211996.htm.

[8] 马德浩.新时代我国高校体育发展的使命、挑战与对策 $[\mathrm{J}]$. 体育学刊,2018,25(5):5-12。

[9] 王运武,于长虹.智慧校园:实现智慧教育的必由之路[M]. 北 京: 北京电子工业出版社,2016:12。

[10] 周婧,王晓楠.人工智能时代信息技术教学模式探究 [J].计算 机教育,2017,(12):109-112。

[11] 潘绍伟,于可红. 学校体育学 $[\mathrm{M}]$. 北京: 高等教育出版社, 2016: 78。

[12] 教育部.关于印发《高等学校体育工作基本标准》的通知 [EB/OL].[2014-06-12].http://www.moe.gov.cn/srcsite/A17/m oe_938/s3273/201406/t20140612_171180.html.

[13] 叶帅华.“互联网+”背景下高校教育教学方式改革思考 [J].高 教学刊,2019(16):149-151。

[14] 顾海勇,郑军,丁润冲,高德霞.学校体育评价系统的研制与开 发 [J].体育文化导刊,2015,(12):131-135。

[15] 国家中长期教育改革和发展规划纲要（2010-2020年） [EB/OL].[2010-07-29].http://old.moe.gov.cn/publicfiles/busin ess/htmlfiles/moe/info_list/201407/xxgk_171904.html?authke $\mathrm{y}=$ gwbux. 